2020, Volume 14, International Conference Innovative Business Management \& Global Entrepreneurship (IBMAGE 2020), pages: 256-269 |

https://doi.org/10.18662/lumproc/ibmage2020/20

\section{Approaches to Measurement of Well-being: Case of the Republic of Moldova}

\section{Tatiana GUTIUM ${ }^{1}$}

${ }^{1}$ National Institute for Economic Research, Chisinau, Republic of Moldova, gutium.tatiana1@gmail.com
Abstract: The development strategy of a modern state is oriented towards ensuring economic growth, increasing the wellbeing of citizens and reducing the level of poverty. The COVID19 pandemic had a negative impact on national economies, including the economy of the Republic of Moldova. That is why, the assessment of well-being, identify impact factors, the elaboration of recommendations for increasing well-being become current. Contemporary approaches to quantifying wellbeing focus on both the economic and social spheres. In this study are identified the weaknesses and strengths of the wellbeing indices, the dynamics of two composite welfare indices have been analyzed. In the research process, the influence of different factors was identified and their influence on the wellbeing of citizens and living standards was estimated. Applying the method of correlation and regression analysis, and using the software Eviews 9 were developed two multifactorial linear regression models: a model of the well-being and a model of living standard of population of the Republic of Moldova. Based on the analysis of the pillars of the Legatum Prosperity Index and the components of the Social Progress Index, priority sectors were identified, such as: health care, education, economic quality, enterprise conditions, environmental quality. At present, it is necessary to promote strategies to ensure sustainable economic growth, which will inevitably lead to an increase in the well-being of the local population.

Keywords: Composite well-being indices, GDP per capita, living standard, minimum level of existence, multifactorial linear regression model, statistical test.

How to cite: Gutium, T. (2020). Approaches to Measurement of Well-being: Case of the Republic of Moldova. In M. W. Staniewski, V. Vasile, \& A. Grigorescu (vol. ed.), Lumen Proceedings: Vol. 14. International Conference Innovative Business Management \& Global Entrepreneurship (IBMAGE 2020) (pp. 256-269). Iasi, Romania: LUMEN Publishing House.

https://doi.org/10.18662/lumproc/ibmage2020/20 


\section{Introduction}

The COVID-19 pandemic has meaningfully affected the well-being of the population of different countries. A temporary but significant decrease in the volume of international exchange of goods and services, the introduction of quarantine have led to the suspension of business activities in certain sectors, especially those related to the provision of services to the population, such as food, recreation, dentistry, personal hygiene (beauty salons), etc. These changes have led to lower incomes, higher unemployment, higher levels of poverty and stress. However, the depth of these changes differs from country to country.

Revealing the social consequences of the created situation, finding ways out, restoring and increasing the well-being of the citizens of the Republic of Moldova are among the top priorities of the state. The establishment of approach of measuring well-being, which is suitable for the Republic of Moldova is very actual. This approach should be able to estimate the effectiveness of public policy, especially social policy.

\section{Problem Statement}

The well-being of population is studying by representatives of the scientific community from different countries. According to the followers of the classical school, the well-being can be assessed as the totality of goods and services per capita. Since the total volume of goods depends on the factors of production, on the available resources, these factors affect not only the aggregate supply and economic growth, but also the level of wellbeing.

Among the first to develop a mathematical approach to measuring well-being were Abram Bergson and Paul Samuelson. P. Samuelson, nominated for the David A. Wells Prize and the John Bates Clark Medal, in his study "Foundations of Economic Analysis" was based on the results of Abram Bergson's research and using a mathematical formula had assessed the welfare of the population [6].

All well-being indices can be divided into two groups:

$>$ The indices which are based on the Gross Domestic Product (GDP) adjustment;

$>$ Composite indices.

Welfare indices such as the Measurable Economic Welfare (MEW), the Index of Sustainable Economic Welfare (ISEW), the Economic Aspects of Welfare (EAW), the Genuine Progress Indicator (GPI), were developed on the basis of the principle of adjusting GDP taking into account 
environmental and social factors. These indices have weaknesses and strengths. Strengths: these indices take into account the impact of negative externalities on economic growth and reduction of natural resources; they reflect non-commercial factors, public services that bring benefits to members of society. Weaknesses: there are lack of statistical data on the impact of ecological factors on welfare; the evaluation of negative externalities is difficult and expensive, which creates impediments to the periodic evaluation of the welfare index; there is lack of consensus on the sign of some components of the index in the calculation algorithm.

One of the composite indices of well-being is the Quality of Life Index (QLI), which was developed in 2005 by The Economist Intelligence Unit and consists of nine components [1]. Today QLI is calculated for 80 countries, Moldova is not on this list.

The British analytical center The Legatum Institute has been evaluating the Legatum Prosperity Index (LPI) for 11 years (2009-2019) in the context of different countries. LPI is a composite index, which in the early years consisted of 8 pillars, and today includes 12 pillars.

In addition to the listed indicators for assessing the well-being of the population, a number of other indices are used in world practice, such as: the Social Progress Index (SPI), the Index of Sustainable Economic Welfare (ISEW), the Genuine Progress Indicator (GPI), the Human Development Index (HDI), the Gross National Happiness (GNH), the World Happiness Index (WHI), the Better Life Index (BLI), the Green GDP, the Genuine Wealth Index (GW), the Sustainable Net Benefit Index (SNBI), etc.

Since the methodology for calculating composite indices changes periodically, they cannot be used to elaborate multifactorial regression models. To obtain a reliable model, the data sample must be relatively large and the components of the series must be comparable.

Several studies have been devoted to the problem of assessing the well-being of the population of the Republic of Moldova. Elena Gorelova and Anatoly Rojco studied the impact of prices on the well-being of the population in terms of statistical indicators [2]. IDIS Viitorul researched the area of poverty reduction policy in Moldova [4]. Svetlana Gorobievsky assessed the social well-being of the citizens of Moldova [3]. However, a multifactorial linear regression model of well-being and a regression model of living standard of population of Moldova, which would allow estimating the influence of the promoted policies has not been developed yet.

The novelty of this article is in the development of two multifactorial linear regression model of the well-being and living standard of the population of the Republic of Moldova. These models were used in the development of recommendations for public policy, especially social policy. 


\section{Research Questions/Aims of the research}

The aims of this study are to develop two multifactorial linear regression models: a model of the well-being and a model of living standard of the population of the Republic of Moldova, identifying factors for their growth, taking into account the specifics of the Moldovan economy and to use obtained results in elaboration of recommendations for increasing wellbeing. The following objectives have been set to achieve this goal:

$>$ Determining priority directions of the public policy of the Republic of Moldova based on the analysis of the dynamics of the composite indices of the population's well-being;

$>$ Elaboration of a multifactorial linear regression model of the well-being of the population;

$>$ Development of a multifactorial linear regression model of living standard of the population;

$>$ Elaboration of recommendations for increasing the well-being of the population.

\section{Research Methods}

Methods of correlation and regression analysis, as well as tabular and graphical methods of visualizing evolution of indicators were used as research tools. The following software packages were used to process statistical information: EViews 9.0, MS Excel.

Statistical data of National Bureau of Statistics of the Republic of Moldova, reports of the Legatum Institute and Global Social Progress Index reports were the information and empirical base of the study.

The sample is determined based on the range of available statistics and the compatibility of the data series. The years of modification of the index estimation methodology are taken into account. For example, the Social Progress Index has been evaluated by the organization Social Progress Imperative, within six years (2014-2019), and the Legatum Prosperity Index has been estimated within 11 years (2009-2019). In the period 2009-2015, the Legatum Index includes 8 pillars, in the period 2016-2018 - 9 pillars, but in 2019 year - already 12 pillars. According to the new methodology, this index was recalculated only for 2009. Therefore, a comparative analysis was carried out the level achieved by the pillars of the Legatum Prosperity Index in 2019 year compared to 2009 year.

The multifactorial linear regression model of the well-being of the population (case of the Republic of Moldova) was developed based on series of annual statistical data for 20 years (2000-2019). The National Bureau of Statistics (NBS) of the Republic of Moldova started to provide information 
on living standards since 2006 year. Consequently, the multifactorial linear regression model of the living standards of population was developed based on series of annual statistical data for the years 2006-2019.

In 2018, the NBS proceeded to estimate the Gross Domestic Product (GDP) according to the new methodology of "the United Nations System of National Accounts (SNA), version 2008 / European System of Accounts, version 2010 (SNA, UN-2008 / SEC-2010)" [8]. Therefore, series of statistical data of GDP were recalculated according to the new methodology in order to ensure compatibility.

\section{Findings}

\subsection{Evolution of the composite indices of the well-being of population of the Republic of Moldova}

The Legatum Prosperity Index is a composite index. In 2019, the Republic of Moldova ranked 81st (of 167 countries) in the Legatum Prosperity Index [9]. Despite the fact that the highest rating was recorded by the "Education" pillar, this level is still 9 positions lower than in 2009 (Figure 1).

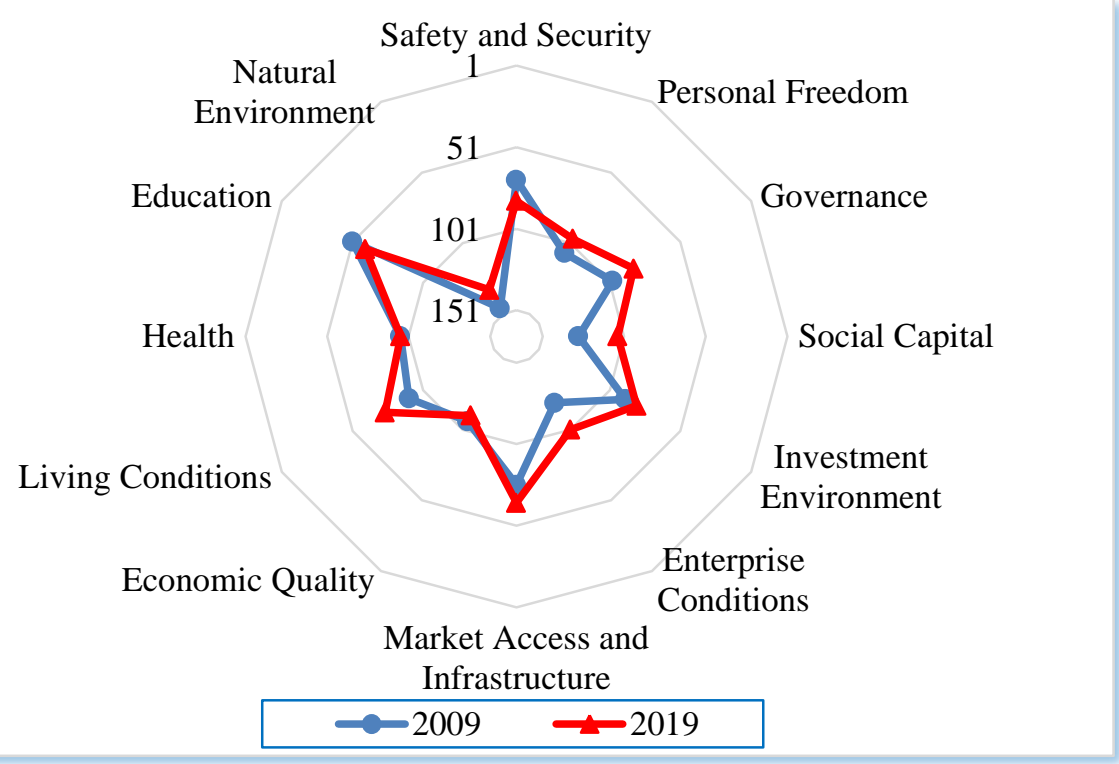

Figure 1. Radar chart of pillars of the Legatum Prosperity Index of the Republic of Moldova in 2009 and 2019, rank

Source: Author results and representation 
This decline was influenced by the decrease in the number of primary and secondary education institutions [5] and quality of education (Figure 2), which led to move down 32 positions in the rating of primary education and 12 positions in the rating of secondary education. During the analysed period, the education pillar reached the lowest rating the $72 \mathrm{nd}$ position in 2017 , when the number of primary and secondary education institutions significantly decreased.

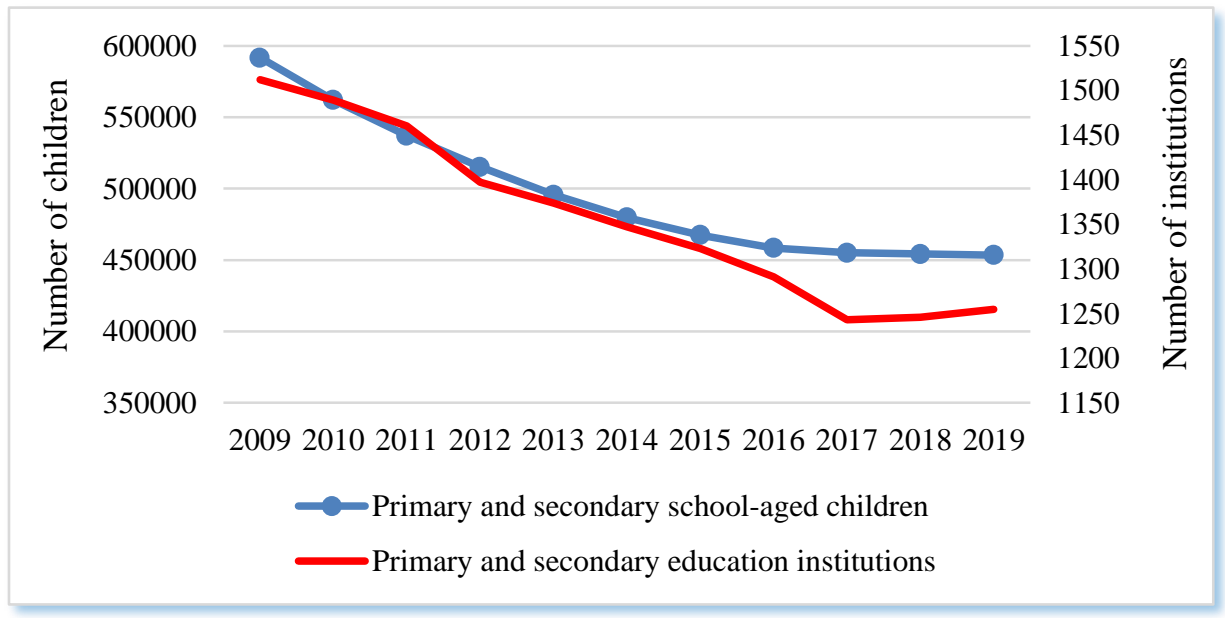

Figure 2. Evolution of primary and secondary school-aged children and education institutions, 2009-2019

Source: Author results and representation

Rank of the Republic of Moldova dropped by thirteen positions on the pillar "Safety and security" and by four positions on "Economic quality" in 2009-2019. The causes of these decreases were:

$>$ a growth (according to the survey of respondents) of political terror, of extrajudicial killings, of use of torture, of political imprisonment, of business costs of crime and violence, of business costs of organized crime;

$>$ a reduction of gross savings (from $23.3 \%$ in 2009 to $14.9 \%$ in 2019), of high-tech manufactured exports (from $1.9 \%$ to $0.5 \%$ ), of economic complexity (from 0.3 to -0.1), of patent applications (from 130.6 patents to 1 million people up to 29 patents), of waged and salaried workers (from $68.0 \%$ to $65.4 \%$ ) [9].

During the reporting period, the Republic of Moldova registered remarkable evolutions on the "Social capital" pillar, on the "Enterprise conditions" and "Living conditions" pillars. They have moved up with 24, 19 and 17 positions accordingly. This progress was caused by: 
$>$ an increase of voiced opinion to a public official (from $20.0 \%$ in 2009 to $23.0 \%$ in 2019), of the help from family and friends when in trouble (from $85.0 \%$ to $88.0 \%$ );

$>$ a growth (according to the respondents) of market-based competition, of efficiency of antitrust policy, of degree of protection of the rights of private companies;

$>$ a decrease of number of tax payments (from 53 per year to 10), the time required to launch the business;

$>$ a reduction of poverty rate at national poverty lines (from $26.4 \%$ in 2009 to $9.6 \%$ in 2019 ), of poverty rate at $\$ 1.90$ a day (from $1.1 \%$ to $0.1 \%$ ), of poverty rate at $\$ 3.20$ a day (from $7.8 \%$ to $1.1 \%$ ), of poverty rate at $\$ 5.50$ a day (from $31.5 \%$ to $16.3 \%$ ), of prevalence of stunting in children under-5 (from 11.3\% to $6.4 \%$ ), of prevalence of wasting in children under-5 (from 5.8\% to $1.9 \%$;

$>$ an increase of availability of adequate food (from $30.0 \%$ to $35.9 \%$ ), of households with a refrigerator (from $78.0 \%$ to $87.7 \%$ ) [9].

The other composite index of well-being of population is the Social Progress Index (SPI). This Index is evaluated by the organization Social Progress Imperative during 2014-2019 in the division of countries, including the Republic of Moldova. SPI is assessed based on answers to "three questions:

1. Does the state provide the essential needs of citizens?

2. Are citizens provided with housing to improve and maintain their well-being?

3. Is it possible for all citizens to reach their full potential?

These questions delineate the three dimensions of social progress: basic human needs, foundations of well-being and opportunity" [7]. Each dimension comprises four specific components, therefore, there are 12 in total.

During 2014-2019, the Republic of Moldova has risen from 81st to 70th position. The rank increased in 10 components (of 12). The decrease of the score was registered in two components: access to advanced education (21.16 points less), inclusiveness (2.31 points less) (Figure 3).

This decline was caused by a reduction of years of tertiary schooling (down to 1.93 years in 2019), of equality of political power according by gender (down to 1.44 points), of equality of political power by social group (down to 1.71 points). 
In 2019 Moldova obtained the highest performances on the following components (Figure 3): nutrition and basic medical care (92.85 points); access to basic knowledge (87.69 points); shelter (86.59 points); access to information and communication (82.01 points).

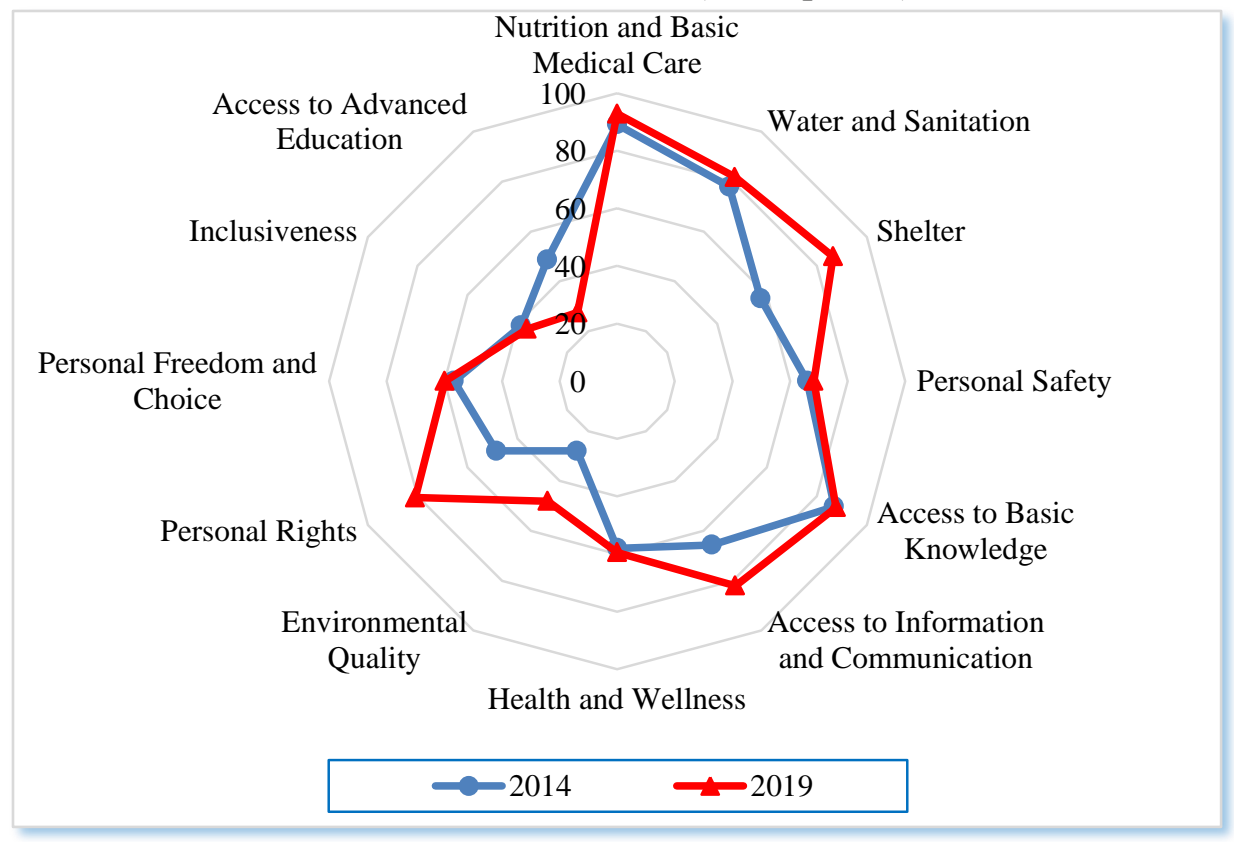

Figure 3. Radar chart of components of the Social Progress Index of the Republic of Moldova in 2014 and 2019, score

Source: Author results and representation

The lowest scores were recorded for components: access to advanced education (27.46 points); inclusiveness (36.17 points); environmental quality (48.09 points); health and wellness (59.44 points).

The pillars of the Legatum Prosperity Index and the components of the Social Progress Index which have reached low scores, identify vulnerable areas and sectors where exactly deficiencies occur. This kind of analysis helps us to set priority directions of public policy. In case of the Republic of Moldova priority directions are

\footnotetext{
$>$ health care,

$>$ education,

$>$ economic quality,

$>$ enterprise conditions,

$>$ environmental quality.
} 


\subsection{Multifactorial linear regression model of well-being of population of the Republic of Moldova}

Assessment of the level of well-being involves the development of a model of the dependence of GDP per capita on economic and social factors. For the study, a system of indicators was formed based on data of the National Bureau of Statistics of the Republic of Moldova, which is presented in Table 1.

Table 1. System of indicators characterizing the well-being of the population

\begin{tabular}{clc}
\hline Designation & \multicolumn{1}{c}{ Indicator } & Unit \\
\hline $\mathrm{x}_{1}$ & Average gross monthly earnings & lei \\
$\mathrm{x}_{2}$ & The average size of the monthly old-age pension & lei \\
$\mathrm{x}_{3}$ & Minimum level of existence & lei \\
$\mathrm{x}_{4}$ & Occupancy rate & $\%$ \\
$\mathrm{x}_{5}$ & Unemployment rate & $\%$ \\
$\mathrm{x}_{6}$ & Number of employed persons per pensioner & person \\
$\mathrm{x}_{7}$ & Migration growth per 10,000 people & person \\
$\mathrm{x}_{8}$ & Birth rate (per 1000 people) & person \\
$\mathrm{x}_{9}$ & Total area of residential premises, accounting in & square \\
& average per inhabitant & meters \\
$\mathrm{x}_{10}$ & Number of hospital beds (per 10 000 & beds \\
& population) & cases \\
$\mathrm{x}_{11}$ & Number of registered crimes per 100,000 & \\
& population &
\end{tabular}

Source: Author selection and conceptualization

We will formulate and test the hypothesis that there is an interdependence between well-being and the system of indicators from Table 1. GDP per capita is used as an indicator of well-being.

The null hypothesis $\mathrm{H} 0$ is that there is no multifactorial linear regression between GDP per capita and the indicators from Table 1. According to the alternative hypothesis $\mathrm{H} 1$, the described relationship exists. Three multifactor linear regression models were developed and they are tested in Table 2. 
Table 2. Testing the null hypothesis that

the regression parameters are equal to zero

\begin{tabular}{ccccccc}
\hline \multirow{2}{*}{$\begin{array}{c}\text { Exogenous } \\
\text { variables }\end{array}$} & \multicolumn{2}{c}{ First model } & \multicolumn{2}{c}{ Second model } & \multicolumn{2}{c}{ Third model } \\
\cline { 2 - 7 } & t-statistic & p-value & t-statistic & p-value & t-statistic & p-value \\
\hline $\mathrm{x}_{1}$ & 2.8333 & 0.022 & 12.6032 & 0.000 & 11.9106 & 0.000 \\
$\mathrm{x}_{2}$ & -0.4114 & 0.692 & - & - & - & - \\
$\mathrm{x}_{3}$ & 1.1006 & 0.303 & - & - & - & - \\
$\mathrm{x}_{4}$ & 0.5544 & 0.595 & - & - & - & - \\
$\mathrm{x}_{5}$ & 0.4022 & 0.698 & - & - & - & - \\
$\mathrm{x}_{6}$ & -0.7795 & 0.458 & - & - & - & - \\
$\mathrm{x}_{7}$ & 2.3512 & 0.047 & 7.2158 & 0.000 & 6.5534 & 0.000 \\
$\mathrm{x}_{8}$ & -2.3269 & 0.048 & -1.7931 & 0.093 & - & - \\
$\mathrm{x}_{9}$ & 1.4476 & 0.186 & 1.9793 & 0.066 & 3.2561 & 0.005 \\
$\mathrm{x}_{10}$ & -1.7796 & 0.113 & - & - & - & - \\
$\mathrm{x}_{11}$ & -0.4781 & 0.645 & - & - & - & - \\
Marginal & & & & & & \\
level of the & 2.2622 & 0.050 & 2.1190 & 0.050 & 2.1098 & 0.050 \\
test & & & & & & \\
\hline
\end{tabular}

Source: Author results

Analysing t-statistic and p-value we conclude that only in the case of model 3 the null hypothesis that the parameters are equal to zero is rejected and the alternative hypothesis is accepted, that the coefficients of linear regression are different from zero. As the result, models 1 and 2 are rejected and model 3 is accepted.

The regression analysis made it possible to identify the most significant factors affecting the well-being of the population of the Republic of Moldova:

$y=-37634.482+5.766 x_{1}+333.576 x_{7}+2173.279 x_{9}$

where: $y-$ GDP per capita, current price, lei.

It is necessary to continue testing this model. The results are shown in Table 3. 
Table 3. Statistical testing of the third model

\begin{tabular}{lc}
\hline \multicolumn{1}{c}{ Statistical tests } & Value \\
\hline R-squared & 0.997828 \\
Adjusted R-squared & 0.997421 \\
F-statistic & 2450.124 \\
Probability (F-statistic) & 0.000000 \\
Akaike info criterion & 16.52163 \\
Schwarz criterion & 16.72077 \\
Hannan-Quinn criterion & 16.56050 \\
\hline
\end{tabular}

Source: Author results

According to the results obtained in Table 3, the multifactorial linear regression (third model) is significant. This model demonstrates that the most significant impact on well-being of population has the following factors: average gross monthly earnings; migration growth per 10,000 people; total area of residential premises, accounting in average per inhabitant.

\subsection{Multifactorial linear regression model of living standard of population of the Republic of Moldova}

As part of the analysis of the well-being of the population, the living standard is considered as a system of quantitative indicators that characterize incomes, expenditures, living conditions. The correlation between the wellbeing and the living standard can be expressed using the following model of simple linear regression:

$y=-10011.186+26.771 z$

$R^{2}=0.993997$

where: $\mathrm{z}$ - living standard (average monthly disposable income per capita), lei;

$\mathrm{R}^{2}-\mathrm{R}$-squared.

Using step-by-step algorithms for including significant and excluding insignificant variables, a regression model of living standard of population of Republic of Moldova was obtained:

$z=887+0.67 x_{2}+0.54 x_{3}+8.36 x_{7}-71.33 x_{8}-64 D_{12}$

where: $\mathrm{D}_{12}-$ dummy variable (it takes value 0 in every year, except 2012; in this year dummy variable takes value 1 ).

This model is statistical tested; the results are shown in Table 4. 
Table 4. Statistical testing of the model of living standard

\begin{tabular}{lc}
\hline \multicolumn{1}{c}{ Statistical tests } & Value \\
\hline R-squared & 0.995835 \\
Adjusted R-squared & 0.993231 \\
F-statistic & 382.5195 \\
Probability (F-statistic) & 0.000000 \\
Akaike info criterion & 10.68687 \\
Schwarz criterion & 10.96075 \\
Hannan-Quinn criterion & 10.66152 \\
\hline
\end{tabular}

Source: Author results

The multifactorial linear regression model of living standard of population (equation 4) shows that the average size of the monthly old-age pension, the minimum level of existence, the migration growth per 10,000 people have a positive impact, but the birth rate (per 1000 people) has negative impact.

According to the model, the increase of the birth rate leads to the decrease of the living standard. To explain why this parameter of regression is negative, it is analysed the balance of income and expenditure of the population according to the composition of the household.

Table 4. Savings (+) / deficit (-) of resources, by household composition, 2019 year

\begin{tabular}{rcc}
\hline & $\begin{array}{c}\text { Savings }(+) / \text { deficit } \\
(-) \text { monthly average, } \\
\text { lei }\end{array}$ & $\begin{array}{c}\text { Share of total } \\
\text { disposable } \\
\text { income, } \%\end{array}$ \\
\hline With children & -80.4 & -3.28 \\
of which with: & & \\
1 child & 62.8 & 2.14 \\
2 children & -136.2 & -5.77 \\
3 children and more & -239.3 & -14.25 \\
Without children & 272.0 & 8.19 \\
\hline
\end{tabular}

Source: Author results 
Hence, the size of the allowances for families with children is not enough. So, one of the social policies that Moldova needs to promote is the significant support of families with many children ( 2 children and more).

The recommendations for increasing the well-being of the population are: ensuring the right to enrol in the primary school in the locality of residence by reopening closed schools or building new schools; improving the quality of vocational training and advanced training of university graduates by modifying study programs in accordance with the changes taking place in science and society; further promotion of the "First House" program; elaboration and promotion of the state program for supporting families with 2 children and more; increasing access to essential health services; raise the quality of healthcare; promoting mass vaccination and immunisation campaigns; ensuring the growth of gross savings by elaborating and promoting the state program for sustainable growth of the national economy and increasing competitiveness; improving the quality and competitiveness of exports; increasing exports of high-tech products; reducing the burden of government regulation; increasing the availability of qualified personnel; increasing water quality; providing renewable water resources; regulating the use of pesticides.

\section{Discussions}

The developed multifactorial linear regression models can be used to estimate the effectiveness of the promoted social policies. However, because the economy is not static and could appear new circumstances and new wellbeing impact factors, it is necessary to revise periodically the regression coefficients. Some of these circumstances may be predictable, but another of these are unpredictable.

\section{Conclusions}

The purpose of the study and set objectives have been achieved. Based on the analysis of the Legatum Prosperity Index and the Social Progress Index, the following priority directions of the public policy of the Republic of Moldova were determined: health care, education, economic quality, enterprise conditions, environmental quality.

Several multifactorial linear regression models have been developed. Applying statistical tests, two models were chosen:

$>$ Multifactorial linear regression model of well-being of population of the Republic of Moldova (equation 1);

$>$ Multifactorial linear regression model of living standard of population of the Republic of Moldova (equation 4). 
These models allowed to identify factors for growth the well-being and living standard of population of the Republic of Moldova, such as: the average gross monthly earnings; the migration growth per 10,000 people; total area of residential premises, accounting in average per inhabitant; the average size of the monthly old-age pension.

Based on the research results, the recommendations for increasing well-being were elaborated.

\section{References}

[1] Economist [nternet]. The Economist Intelligence Unit's quality-of-life index; 2005 [cited 2020 April 20]. Available from: https://www.economist.com/media/pdf/QUALITY OF LIFE.pdf

[2] Gorelova E, Rojco A. Influența prețurilor asupra bunăstării populației prin prisma indicatorilor statistici. Chisinau: CISR; 2010. 37.

[3] Gorobievsky S. Evaluarea bunăstării şi diferenței sociale a populației Republicii Moldova (Partea I). Meridian Ingineresc. 2011; 1: 40-45.

[4] IDIS Viitorul [Internet]. Studiul politicilor de reducere a saraciei in Republica Moldova; 2015 [cited 2020 May 15]. Available from: http://www.viitorul.org/files/4885299 md studiul politi.pdf

[5] National Bureau of Statistics of the Republic of Moldova [Internet]. Statistical databank [cited 2020 July 30]. Available from: https://statistica.gov.md/pageview.php?l=en\&idc $=407 \&$ nod $=1 \&$

[6] Samuelson P. Foundations of Economic Analysis. Enlarged edition. Harvard: Harvard University Press; 1983. 604 p.

[7] Social Progress Imperative [Internet]. 2019 Social Progress Index Executive Summary; 2019 [cited 2020 May 7]. Available from: https://www.socialprogress.org/assets/downloads/resources/2019/2019Social-Progress-Index-executive-summary-v2.0.pdf

[8] System of National Accounts 2008 [Internet]. New York: The United Nations; 2009 [cited 2020 April 12]. 662 p. Available from: https://unstats.un.org/unsd/nationalaccount/docs/SNA2008.pdf

[9] The Legatum Prosperity Index [Internet]. Moldova country profile; 2019 [cited 2020 May 18]. Available from: https://prosperitysite.s3accelerate.amazonaws.com/2715/7408/3745/Moldova 2019 PIcountryprof ile.pdf 